Área Abierta. Revista de comunicación audiovisual y publicitaria

ISSN: 2530-7592 / ISSNe: 1578-8393

\title{
La reivindicación de la corporeidad como transgresión en Los idiotas
}

\author{
Enric Antoni Burgos Ramírez ${ }^{1}$
}

Recibido: 4 de diciembre de 2020 / Aceptado: 20 de enero de 2021 / Publicado: 26 de febrero de 2021

Resumen. El episodio de la orgía de Los idiotas (Dogme \#2. Idioterne, Lars von Trier, 1998) acaparó gran parte de las polémicas que suscitó la película. Lejos de suponer una mera provocación, la escena desempeña un papel sustancial en la cinta. El presente artículo se propone desplegar la poliédrica reivindicación del cuerpo que el pasaje exhibe y que resulta extrapolable al conjunto del filme. Para ello, el análisis textual del fragmento será engarzado con los planteamientos de Cavell y Deleuze sobre el sujeto y cine encarnados. La atención a aspectos temáticos revelará cómo el pasaje apunta al cuerpo como vía de expresión de la comuna idiota y ejerce de punto de inflexión clave en la historia. Por otra parte, la fijación de la cámara por los cuerpos y el comportamiento somático de esta se presentarán como las dos maneras con las que el film efectúa su reivindicación formal de la corporeidad.

Palabras clave: Los idiotas; Lars von Trier; Dogma 95; Cuerpo Humano; Cámara; Cine Pornográfico

\section{[en] The Claim of Corporeity as Transgression in The Idiots}

\begin{abstract}
The orgy's episode in The Idiots (Dogme \#2. Idioterne, Lars von Trier, 1998) monopolized a large part of the controversy that the film caused. Far from implying a mere provocation, the scene plays a substantial role in the motion picture. This essay aims to expound the polyhedral claim of the body that the passage shows and which happens to be extrapolable to the film as a whole. To do this, the textual analysis will be combined with Cavell's and Deleuze's approaches to embodied subject and cinema. Attention to thematic aspects will reveal how the passage points to the body as a way of expression for the idiot gang and functions as a turning point in the story. On the other hand, the camera's fixation with bodies and its somatic behaviour will be presented as the two main ways in which the film accomplishes its formal claim of corporeity.
\end{abstract}

Keywords: The Idiots; Lars von Trier; Dogma 95; Human Body; Camera; Pornographic Films

Sumario. 1. Introducción. 2. Marco teórico y metodología. 3. El cuerpo como vía de expresión en la comuna idiota. 4. La técnica del point and shootstyle. 5. Conclusiones. 6. Bibliografía.

Cómo citar. Burgos Ramírez, Enric Antoni (2021). La reivindicación de la corporeidad como transgresión en Los Idiotas. Área Abierta. Revista de comunicación audiovisual y publicitaria 21 (1), 77-92, https://dx.doi.org/10.5209/arab.72848

\footnotetext{
Universidad de Valencia (España)

E-mail: enric.burgos@uv.es

ORCID: https://orcid.org/0000-0003-3721-2472
} 


\section{Introducción}

El estreno en Cannes de las primeras películas de Dogma 95 resulta igual de provocador que la puesta en escena con la que, tres años antes, von Trier dio a conocer el movimiento en el Odéon Cinéma de París. Los films presentados por los dos firmantes del Manifiesto y Voto de castidad (Vinterberg \& von Trier, 1995) ${ }^{2}$ de la corriente danesa no dejan indiferente a nadie, aunque por motivos distintos. Los premios y elogios cosechados por Celebración (Dogme \#1. Festen, Thomas Vinterberg, 1998) contrastan con los duros ataques que, de manera generalizada, recibe Los idiotas (Dogme \#2. Idioterne, Lars von Trier, 1998). Solo un sector de la crítica francesa aplaude el experimento de von Trier mientras que la prensa internacional parece menos interesada en valorar cinematográficamente Los idiotas que en hablar de su políticamente incorrecto enfoque del tema de la discapacidad, del debate que la película provoca en determinados círculos feministas ${ }^{3}$ o del revuelo que causan sus escenas de carácter sexual.

Quizá es esta última cuestión la que mayor controversia genera. Las imágenes de sexo explícito de Los idiotas comportan la censura en numerosos países. La película es prohibida en Irlanda y en Japón se exhibe una versión censurada. En Estados Unidos el film se estrena dos años más tarde incluyendo bandas negras que ocultan determinadas partes del cuerpo. En el Reino Unido, Los idiotas sienta precedente al no ser finalmente clasificada para mayores de dieciocho años y una situación similar se vive en Noruega, donde, tras cierto debate, se decide mantener en la cinta las imágenes que muestran erecciones. Como contrapartida, estos actos $-\mathrm{o}$ intentos- de censura suponen una publicidad gratuita que beneficia la recaudación, sobre todo en países cercanos a Dinamarca donde la integridad del film es respetada, como Suecia o la propia Noruega (Stevenson, 2005: 188-189).

De entre todos los fragmentos de Los idiotas que cuestionan los criterios establecidos para la consideración de una película como pornográfica destaca aquel en que el grupo de protagonistas celebra una fiesta que deriva en orgía. Para satisfacción de von Trier, y a juzgar por las reacciones internacionales comentadas, el episodio contribuye a que la cinta sea tildada de transgresora, satisfaciendo así los provocadores propósitos del movimiento. Efectivamente, haciendo de los genitales el motivo principal de ciertos planos -y muy especialmente, de los masculinos y en erección- la cinta ataca la corrección política de esa tendencia cinematográfica dominante que el Manifiesto Dogma no duda en calificar de burguesa.

En el nuevo milenio, diversos autores se han encargado de explorar con sus películas el permeable -y a menudo hipócrita- umbral de la pornografía. Pueden servir como ejemplo The Brown Bunny (Vincent Gallo, 2003), 9 Songs (Michael Winterbottom, 2004), Lie with Me: El diario intimo de Leila (Lie with Me, Clement Virgo, 2005), Canino (Kynodontas, Yorgos Lanthimos, 2009), los dos volúmenes de Nymphomaniac (2013) del mismo von Trier o la más reciente Love (Gaspar Noé, 2015).

Pese a que la web oficial de Dogma 95 desapareció en 2005, hoy en día podemos acceder a través del mismo dominio -www.dogme95.dk- a parte de los contenidos de la web originaria, entre ellos, el Manifiesto del movimiento y el decálogo que la hermandad se autoimpuso.

3 Obviamente, también hubo voces que rebatieron la acusación de machismo que recibió Los idiotas. De entre la producción científica que se acerca al film desde una óptica feminista -y próxima a nuestros planteamientosdestacamos el artículo "Kristeva and The Idiots" (Sjöholm, 2003). 
De alguna manera, estos títulos serían continuadores de esa tendencia en el cine de autor de finales de los noventa que, como afirman Mendíbil, García García y García Guardia (2017: 159), se caracteriza por la inserción de fragmentos pornográficos y que encuentra precisamente en Los idiotas su primer referente.

La condición de pionera en estas lides de la cinta de von Trier nos anima a centrar en ella nuestra atención y a convertir el episodio orgiástico en el núcleo de nuestro análisis. Más allá del aludido rédito publicitario que la escena otorgara al film y de la mencionada impugnación de las fronteras de la pornografía que implicara, nuestro objetivo consistirá en valorar la coherencia temática y formal que la escena mantiene con el resto del film y, en última instancia, en mostrarla como condensación paradigmática de las estrategias con las que la película apunta hacia una reivindicación del cuerpo que se manifiesta de maneras diversas y complementarias.

Para llevar a cabo nuestro propósito procederemos al análisis de la escena, considerándola en primer lugar desde una perspectiva temática que contribuirá a integrar el fragmento en la totalidad de la historia de Los idiotas y nos permitirá apreciar la concepción del cuerpo como medio primario para la comunicación que destila la película. A continuación, derivaremos la atención hacia aspectos formales y nos centraremos en la peculiar puesta en cuadro que exhibe el pasaje: a través de la valoración del trabajo de cámara - fijándonos en qué encuadra y cómo lo encuadraaccederemos a los otros dos sentidos en los que juzgamos que la escena materializa su reivindicación del cuerpo. El establecimiento de paralelismos con otros fragmentos nos ayudará a evaluarel grado en el que este discurso somatizado impregna gran parte del metraje.

\section{Marco teórico y metodología}

A lo largo del análisis seguiremos la recomendación de Anne Jerslev (2002: 41) de remitir al conjunto del Proyecto idiota ${ }^{4}$ y complementaremos nuestra lectura con cuestiones contextuales relativas tanto a las circunstancias de la producción como a la inclusión del film en el movimiento Dogma 95. A la vez, nuestra lectura recurrirá a los planteamientos de Stanley Cavell y Gilles Deleuze, un par de filósofos caracterizados no solo por su manifiesto interés en el cine como productor de pensamientovitalsino también por su búsqueda de alternativas al cartesianismo y, en consecuencia, por su apuesta por el cuerpo como elemento ineludible de nuestra condición humana. En efecto, ambos autores rehúsan la escisión res cogitans/res extensa acatada por la filosofía tradicional y se distancian de los planteamientos que la circundan. Rechazan, pues, la supuesta autonomía e incomunicación entre alma y cuerpo, la concepción de este como velo que oculta el alma y como barrera que impide el acceso a las otras mentes, la interpretación de la vida desde el mecanicismo y, en definitiva, los argumentos escépticos cartesianos que concluyen de manera teórica esa negación práctica del cuerpo que llevaba siglos bien asentada en la cultura occidental.

Por su parte, Cavell apunta a la recuperación de lo ordinario como vía para sobrellevar el escepticismo - esto es, esa siniestra manera de habitar el mundo asumida

\footnotetext{
Según Jerslev (2002: 41), Los idiotas no ha de ser valorada como parte de un proyecto en el que aparecen ligados, además del film y su guion, el Manifiesto y Voto de castidad, el diario que el director grabó durante la realización de la película y De ydmygede (Jesper Jargil, 1999), el making of del film de von Trier.
} 
bajo las condiciones de la modernidad-. El restablecimiento de la conexión ordinaria del individuo con el mundo, con los otros y con él mismo pasa por el reconocimiento de la verdad que nos enseña el escepticismo, a saber, que estos vínculos no deben ser entendidos en términos epistemológicos sino existenciales. Y esta triple re-conexión existencial -pática, moral, vivencial- solo es posible si reconocemos el cuerpo y lo reconocemos como la mejor imagen del alma (Cavell, 2009: 167). Para Cavell, por tanto, la existencia humana tiene una base física irrenunciable. Somos criaturas biológicas, encarnadas, sometidas a condiciones físicas: soy cuerpo, mi cuerpo es yo-en el mundo (2003: 501). Y ese cuerpo que soy es el que se muestra a los otros a los que com-padezco y me com-padecen, a esos otros con los que con-verso, con los que con-vivo: porque soy yo-en el mundo-con los otros ${ }^{5}$.

Según Cavell, el cine puede revelarnos lo siniestro de la manera de habitar el mundo asumida bajo las condiciones de la modernidad. Presentándonos el desplazamiento como si fuera nuestra condición natural, el cine puede hacer que nos demos cuenta de lo poco natural que resulta que vivamos manteniendo este mismo tipo de desconexión con el mundo y con nuestros semejantes; en otros términos, que reparemos en que el mundo que vivimos a diario no es una mera proyección y que cuenta con nuestra mediación como seres-en el mundo-con los otros.

También Deleuze otorga un lugar central al cuerpo -y a la creencia en él- en su respuesta al dualismo que marca la filosofía occidental y al nihilismo en que desemboca. Un cuerpo que no es para el francés un obstáculo para el pensamiento, sino aquello en lo que el pensamiento debe sumergirse para alcanzar lo impensado, la vida (1987: 251). La inversión deleuzeana aboga, de esta manera, por remitir el pensamiento a las categorías de la vida, recuperar la creencia en este mundo y potenciar el cuerpo y sus afectos. En esta tarea, el cine desarrolla una labor crucial al ser capaz de mostrar las posibilidades del cuerpo mejor que cualquier otro arte. Y, recíprocamente, "[e]s por el cuerpo -y ya no por intermedio del cuerpo- como el cine contrae sus nupcias con el espíritu, con el pensamiento" (Deleuze, 1987: 251).

Será de importancia para nuestros fines lo que Deleuze presenta como "cine del cuerpo" (1987: 251-270) y que podría definirse como esa práctica fílmica en la que la performatividad reemplaza la causalidad, impidiendo concebir el film como mera reproducción del guion. Dado el alto grado de improvisación y el control relativo que ejercen narrativa y director, este cine del cuerpo mostraría una especial propensión al choque entre lo fílmico y lo metafílmico y, consiguientemente, a la autorreflexión. Nos resultará también relevante el concepto de "imagen-afección" que Deleuze desarrolla en sus anteriores estudios sobre el cine (1984: 131-150). Esta imagen-afección aparece indisolublemente ligada al rostro $-\mathrm{y}$ a su capacidad de traslucir el interior y hacer brotar el afecto- y al primer plano cinematográfico: "no hay primer plano de rostro, el rostro es en sí mismo primer plano, el primer plano es por sí mismo rostro, y ambos son el afecto, la imagen-afección" (1984: 132). Como mantiene Deleuze (1984: 142) siguiendo a Balazs, el primer plano abstrae a su sujeto de las coordenadas espacio-temporales, elevándolo al estado de Entidad. Se genera entonces un espacio afectivo no fijado sino abierto e incierto en el que el afecto invita al espectador a sentir con el personaje y la indeterminación le insta a reflexionar.

La formulación en cursiva la tomamos de Ribes (2009: 213). 


\section{El cuerpo como vía de expresión en la comuna idiota}

Los idiotas nos presenta la historia de un grupo de jóvenes que, liderados por Stoffer, deciden hacerse pasar por personas con diversidad funcional. Pese a que la finalidad última del estrafalario experimento no se nos revela de manera clara, bien es cierto que en diversas ocasiones Stoffer expresa que el juego aspira a obtener el beneficio terapéutico que proporciona el encuentro con nuestro idiota interior y que sistemáticamente reprimimos ${ }^{6}$. Los primeros minutos de la cinta nos permiten apreciar la vertiente más maliciosa de su juego que se manifiesta cuando el comportamiento de los idiotas pone a desconocidos en situaciones comprometidas. A medida que el film avanza, sin embargo, observamos que la comuna alterna sus performances en público con otras simulaciones que tienen lugar en el ámbito más privado. Podemos, pues, distinguir entre dos tipos de acciones dentro del juego idiota. Por una parte, las que implican el contacto con el exterior y que vendrán marcadas por la aversión hacia la convención moral, la ironía y la provocación lanzada contra la burguesía biempensante. Por otra, las acciones internas del grupo que, aunque desenfadadas y a menudo frívolas, nos permiten vislumbrar un cierto anhelo de transformación personal y colectiva.

Tanto en sus performances externas como en las internas -pero sobre todo en estas segundas, donde ubicamos la mencionada orgía- la teatralización del grupo presenta un par de características interrelacionadas que presiden la alternativa personal y (con)vivencial que la comuna persigue durante su efímera existencia y que dan cuenta de su oposición a los parámetros logocéntricos de la cultura moderna: nos estamos refiriendo a la opción de los idiotas por la práctica renuncia al lenguaje verbal y por la reivindicación del cuerpo.

Si la voz analítica del logos ensalzada por la ciencia y la filosofía tradicional se ha encargado de excluir y silenciar el resto de voces, el grupo idiota optará por encontrar su voz en las antípodas del terreno en el que se mueve la cultura moderno-burguesa. A excepción de casos muy puntuales, el idiota interior de los miembros de la comuna no se manifiesta verbalmente, y cuando lo hace, el uso aislado de palabras apenas da pie a una situación comunicativa. Por lo general, y especialmente cuando en sus juegos no participa ningún individuo externo, los idiotas utilizan principalmente sonidos inarticulados para expresarse y, en la mayoría de ocasiones, tan solo el silencio.

La voz del silencio llama así a escena a la voz del cuerpo, de ese cuerpo que, como diría Cavell (2003: 470), no supone un velo para el alma sino que nos ofrece la mejor imagen de esta, de ese cuerpo que no tenemos sino que somos y que está condenado a la expresión. Los anhelos de transformación de la comuna idiota pasan, pues, por creer en el cuerpo o, en palabras de Deleuze (1987: 231), por "[d] evolver el discurso al cuerpo y, para eso, alcanzar al cuerpo anterior a los discursos, anterior a las palabras". La reivindicación de la desnudez y de lo sensual por parte del grupo puede leerse, así, como camino para liberarse de las restricciones de la razón y de la moral conservadora (Rockwell, 2003: 58) y, en definitiva, de la negación de la corporeidad que caracteriza las bases cartesianas de la cultura occidental.

No pasa desapercibida la lectura en clave alegórica del film que nos invitaría a establecer paralelismos entre el proyecto del grupo capitaneado por Stoffer y la aventura dogmática en la que se embarca von Trier junto a su equipo - es decir, ese otro Proyecto Idiota- 
Estas consideraciones nos permiten retornar al episodio de la fiesta que se transforma en orgía y valorar su rol en la historia de la comuna idiota. Bajo este prisma, el pasaje ilustra inmejorablemente cuanto acabamos de mantener. Ya desde el inicio de la celebración, la interacción de los jóvenes idiotizados se limita a lo sensorial: no hay conversación entre ellos, solo sus gritos de emoción y el sonido de los globos que explotan enmudecen puntualmente la canción Vi Er Dem a cuyo son bailan. Sus movimientos espasmódicos, ajenos a cualquier disciplina o aspiración coreográfica, nos aproximan a una suerte de vivencia primitiva del ritmo y la música, a una forma de expresión virgen, no educada y tangiblemente física. Lo primario de la escena llega a su zenit poco después, cuando el grupo se embarca en la orgía. Cuerpos desnudos y expuestos a los otros, que entran colectivamente en contacto, que se ponen en común sin observar la ortodoxia del encuentro sexual. Los gestos rudimentarios y torpes de los idiotas apuntan hacia lo instintivo y corpóreo del acto, hacia la fisicidad más cruda que a menudo se esconde bajo capas de estetizado maquillaje.

La escena alcanza el punto álgido del intento de la comuna por procurar el auténtico contacto entre personas desde unos presupuestos diferentes a los que marcan la vida fuera de la casa en la que se acuartelan, desde unos presupuestos que buscan una comunicación al margen de lo verbal y que ponen de manifiesto la importancia de la dimensión somática de la experiencia al convertir el cuerpo en la principal vía de expresión. Un cuerpo que se afirma en la comuna no solo como condición de posibilidad de la comunicación sino también como medio primario para esta, un cuerpo que se reivindica y que reivindica su peso determinante de cara a alcanzar lo que Cavell denomina proyección empática?

Además de suponer el culmen de las aspiraciones idiotas de los amigos, el episodio de la orgía nos acerca, asimismo, a un punto de inflexión clave en el film:

[T] he spassing in Idioterne reaches a climax in a scene in which the group spasses itself into a collective orgy. The "inner idiot" is exposed -literally- as a collection of desires that are ordinarily suppressed. Once this "truth" has been "forced out of the actors and settings" of Idioterne, the group quickly begins to fall apart [...]. The orgy therefore heralds the reinstatement of the patriarchal order and the return of normality (Simons, 2007: 65).

La escena inmediatamente anterior, sin embargo, ya había dejado entrever el punto de no retorno al que se acercaba la comuna.El comportamiento psicopático de un enloquecido Stoffer cargando contra el funcionario del ayuntamiento había asustado a todos y puesto en entredicho la continuidad del experimento idiota. De hecho, el colapso del líder supone el fin de las acciones externas de la pandilla. La fiesta que deviene orgía con la que los amigos intentan animar al cabecilla no corre mejor suerte y acaba resultando la última performance interna del grupo y recordándonos que el falo es la ley del deseo del padre. Caído el jefe y satisfechos en el juego sexual

\footnotetext{
El acto de proyección empática sería el paso interpretativo que nos lleva de la percepción del cuerpo del otro como objeto sensible hasta su reconocimiento como humano encarnado y animado que reclama un trato diferenciado del que otorgamos a los meros objetos materiales: "Mi identificación de ti como ser humano no es sólo una identificación de ti sino contigo. Esto es algo más que meramente verte. Llamémoslo proyección empática" (Cavell, 2003: 547).
} 
los deseos reprimidos, el anhelo de transformación social y personal se diluye y se impone la vuelta a la normalidad.

El episodio que nos ocupa ofrece, no obstante, un atisbo de esperanza en la escena que lo cierra y que da cuenta del encuentro amoroso que Jeppe y Josephine protagonizan al margen del grupo. Su idiota interior les impulsa a sacar lo que encierran, a saber lo que quieren y a actuar en consecuencia. El propósito transformador del proyecto idiota parece florecer aquí, especialmente en una Josephine que, tras obtener los beneficios terapéuticos de la idiotización, retorna entre lágrimas a la palabra con el "Te quiero" que dedica a Jeppe. Será con la llegada a la comuna del padre de la joven en la escena siguiente cuando mejor podamos entender sus necesidades de cambio. Y es que Josephine ha encontrado en la experiencia comunal la alegría que no le proporcionan ni las pastillas con las que descubrimos que se medica ni una figura paterna ante la cual se muestra incapaz de decidir por sí misma. Su efímero logro, pues, se quiebra en el momento en el que, pese a los intentos desesperados de Jeppe por evitarlo, abandona el chalet en el coche de su padre. La marcha de Josephine convierte en realidad el inicio de la descomposición de la comuna idiota y la reinstauración del orden patriarcal en la historia. En efecto, ya nadie volverá a simular discapacidad. El reto de hacer el idiota en casa o en el trabajo que Stoffer lanza solo consigue desenmascarar definitivamente la inautenticidad y falta de convicción de la pandilla en la causa idiota y precipitar los acontecimientos.

Ahora bien, la actitud de Karen servirá de contrapunto al derrotismo del grupo y confirmará cuanto acabamos de sugerir veladamente a propósito de Josephine, a saber, que las repercusiones enriquecedoras del juego idiota resultan especialmente evidentes en los personajes más damnificados por la idiotización cotidiana a las que somete nuestra sociedad de relaciones deterioradas. Es este el caso de una Karen que necesita expresar el desgarro causado por la muerte de su hijo y liberarse de la opresión familiar: la interpretación idiota de Karen en el hogar es perfecta -auténtica- porque su interpretación es su ser. Frente al racional antirracionalismo que el grupo se ha impuesto, los espasmos discapacitados de Karen transgreden el orden simbólico desde la pura emoción, el único espacio desde el que puede articularse su trauma (Jerslev, 2002: 62).

Tras recibir como respuesta una bofetada por parte de Anders -ese marido que actúa más bien como padre-, Susanne se dirige a la protagonista: "Ya es suficiente, Karen. ¿Nos vamos?". El escueto pero firme "sí" de la mujer, última palabra que oiremos en el film, es el primer paso de una articulación verbal que va más allá del reactivo recurso al silencio como voz del idiota interior, que reconcilia la palabra con el cuerpo e impugna la separación entre este y el alma. La actual capacidad para el discurso de Karen es la base sobre la que reposa su derecho a tener derechos, algo que ahora sabe que podrá aspirar a ver reconocido fuera de los muros de su casa. La ruptura de Karen con su familia supone, así, la consumación de los anhelos transformadores de la causa idiota y un punto central del fin político del film.

Las últimas consideraciones nos permiten apreciar el punto de inflexión que supone el episodio de la orgía en la historia de la comuna, observar hasta qué punto el orden patriarcal va reimponiéndose y valorar el camino divergente que toma Karen en el tramo final de la película. Paralelamente, el tono del film abandona el humor negro que le había caracterizado hasta ese punto y vira definitivamente hacia lo melodramático cuando está en juego mostrar la seriedad y emocionalidad que el juego idiota puede entrañar. A su vez, Los idiotas se va reconduciendo progresivamente en 
estos episodios finales hacia su particular ley del padre, esto es, hacia el orden del relato. Mientras que en la primera mitad del film lo mostrativo es claramente privilegiado frente a lo narrativo en un intento por cumplir con el rechazo a la dramaturgia propuesto por Dogma 95, a partir del episodio de la orgía la sucesión de escenas hace más evidente la relación de causa-efecto que liga las unas con las otras, acercándose así a la manera tradicional de contar del cine hegemónico y a las fórmulas genéricas de las que el movimiento danés pretendía huir.

\section{La técnica del point and shootstyle}

De aquí en adelante trataremos de complementar las recientes consideraciones en torno al contenido del film acudiendo al análisis formal. En última instancia, nuestro objetivo consistirá en señalar la reivindicación del cuerpo que apreciamos en la puesta en cuadro de Los idiotas e iluminar, de este modo, la imbricación de esta con los aspectos temáticos que hemos resaltado. Para ello, conviene que dediquemos previamente unas líneas al que consideramos el elemento más característico de la cinematografía de la película, esto es, a la técnica del point and shoot style con la que von Trier intenta cumplir con las reglas de Dogma 95 y respetar el espíritu que destilan.

La técnica idiota empleada en el rodaje responde a la interpretación que el director hace de la tercera regla que el colectivo se autoimpone con su Voto de castidad. De acuerdo con este precepto, "La cámara ha de sostenerse con la mano. Cualquier movimiento - o inmovilidad-conseguido con la mano está autorizado" (Vinterberg y von Trier, 1995). Algunas versiones del decálogo -como la que aparecía en los extras de los DVD de los films del movimiento- incluían inmediatamente después y entre paréntesis el siguiente añadido: "la película no tiene que ocurrir donde la cámara está situada; el rodaje tiene que ocurrir donde la película tiene lugar". La aclaración ayuda a entender el propósito que subyace a la particular puesta en cuadro que exhibe Los idiotas: para von Trier, y a diferencia de cuanto sucede en los rodajes convencionales, no es la realidad profílmica -incluidos, está claro, los actores- la que debe ajustarse a los imperativos de la cámara, sino todo lo contrario.

En el intento de von Trier de alejarse de los constreñimientos del cine de la industria, las tomas largas y el encuadre móvil -características fundamentales de la improvisación técnica que lleva a cabo el point and shootstyle- marcarán un trabajo de cámara que deposita la confianza en los actores y que exime al director del control que tradicionalmente asume con respecto a la puesta en cuadro. Establecido este contexto, la siguiente idea guiará nuestra indagación de la técnica idiota del film: al recurrir al point and shootstyle, no es tanto la mente del director la que decide racionalmente y a priorisobre el estilo del film, sino los cuerpos de los actores con los movimientos y expresiones que ejecutan en el momento del rodaje, en plena negociación con la realidad. De esta afirmación se derivan ciertas cuestiones entrelazadas de considerable importancia para nuestra lectura que expondremos en los dos próximos subepígrafes.

\subsection{La cámara y su fijación por los cuerpos}

Si nos centramos en la referencia al binomio director-actores de nuestro recién mencionado postulado de partida, podríamos remarcar el servicio que la técnica del point and shoot style presta al terapéutico propósito del director de deshacerse de la obse- 
sión por el control absoluto. A pesar de que en última instancia von Trier no puede desligarse de su responsabilidad sobre el estilo del film -es él el director y quien elige la técnica de grabación empleada, $\mathrm{y}$, además, el principal operador de cámara de Los idiotas-, apostar por el point and shoot style le libera de tomar ciertas decisiones técnicas y le permite centrar su interésen los personajes y en el cuadro de la acción. Un tipo de des-control relativo -o de control compartido con el equipo artístico- viene a sustituir la obsesión por el que podríamos denominar "dominio cinematográfico" de la realidad. Pero lo que más nos interesa destacar en relación con la técnica de grabación empleada en Los idiotas no tiene tanto que ver con la ayuda que presta a la superación de la tradicional posición de autoridad del director frente a su equipo como con aquella otra pérdida de control -estético, en este caso- que la técnica persigue. Por ello, y remitiendo al episodio orgiástico que nos está ocupando, focalizaremos nuestra atención en el binomio mente-cuerpo y en cómo la técnica empleada configura el estilo del film.

Acudiremos en primer lugar al largo plano en el que Susanne trata de huir de los compañeros que intentan persuadirla para que participe en la orgía. Este comienza mostrándonos la espalda de Susanne mientras se encamina a toda prisa hacia la puerta que da acceso al jardín del chalet -imagen 1-. Al salir, la joven es seguida por Stoffer, Axel y Miguel, quienes atraviesan la puerta justo antes de que el operador de cámara reproduzca la misma trayectoria. Los notorios cambios lumínicos afectan a una toma que nos ha llevado mediante la grabación continua desde el interior de la casa hasta el jardín, y que se desarrolla, ya en el exterior, tanto en zonas con luz solar como en áreas situadas a la sombra de los árboles. Los jóvenes persiguen a Susanne del mismo modo como la cámara persigue a los cuatro -imágenes 2 y $3-$. El prolongado plano nos permite apreciar la inestabilidad de la cámara y la deficiente captación de audio al aumentar la distancia entre actores y microfonista. Incluso podemos llegar a oír el ruido extradiegético que los bruscos zarandeos del equipo técnico añaden a la banda sonora. Después de haber rodeado la casa tras Susanne, Miguel consigue derrumbarla y el plano finaliza-imagen 4-.
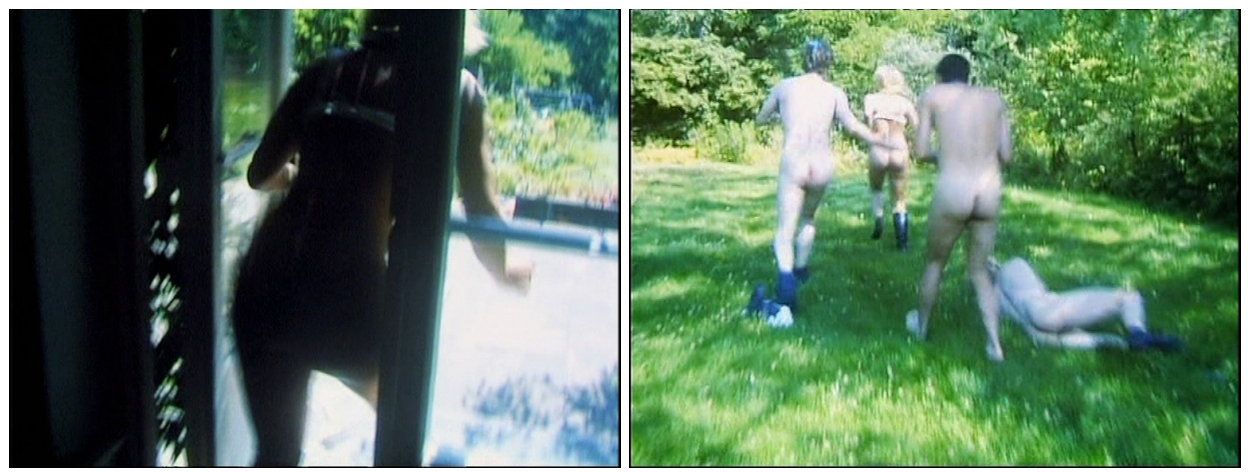

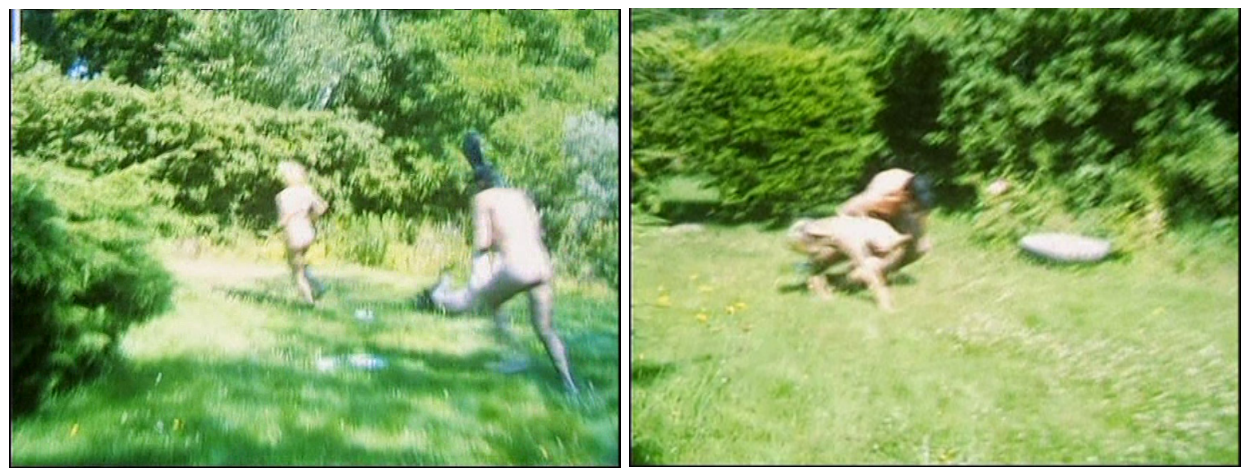

Imágenes 1, 2, 3 y 4. [Fuente: Captura de pantalla]

Estos veinte segundos de metraje sin cortes recogen gran parte de aquello que von Trier se propone con su opción por la técnica del point and shoot style. La cámara al hombro facilita el recurso a un encuadre móvil que reacciona constantemente ante las acciones de los personajes, que encuentra su motivación principal en las expresiones y trayectorias de estos. Los cuerpos de los protagonistas constituyen el tema de los planos, y los encuadres y composiciones permanecen subordinados a su movimiento. La cinematografía de Los idiotas se libera de esta manera de las limitaciones impuestas por guion técnico y storyboardy encaja con la caracterización deleuzeanadel cine del cuerpo.

La película al completo nos ofrece numerosos ejemplos de esto no menos elocuentes, de entre los cuales destacan aquellos en que, como en el último plano referido, la cámara se apresura detrás delos personajes que corren. Pensemos, por ejemplo, en las tomas que cubren la carrera enloquecida de Stoffer tras el vehículo del funcionario o en la posterior captación de la repentina reacción de Jeppe al ponerse a correr en dirección al coche en el que el padre de Josephine se lleva a su hija.

La atención a los cuerpos no se agota, sin embargo, en los diversos planos en los que los personajes son perseguidos mientras exploran y descubren el espacio profílmico con sus trayectorias imprevisibles. De hecho, gran parte de las tomas del film se graban mientras la cámara está situada bien cerca de la acción, sin que ningún desplazamiento de los actores comporte una reubicación notable del operador de cámara. De esta exagerada proximidad hacen gala varias imágenes dedicadas a cubrir el auge de la fiesta sexual. Situada en medio de la acción, la cámara graba con planos cortos una amalgama de cuerpos fragmentados, haciendo de la genitalidad y de los ademanes discapacitados de los personajes sus principales motivos y mostrando las manifestaciones de los cuerpos en toda su crudeza.

Pese a la proximidad entre cámara y actores, el reencuadre en busca de nuevos estimulos constituye igualmente una constante en los planos de corta escala. El interés de la enunciación radica en estos casos en las expresiones y gestos concretos de los personajes. La escena de amor entre Jeppe y Josephine que sirve de coda al pasaje de la orgía, nos ofrece unas cuantas muestras bien significativas del afán de la cámara por escrutar las miradas, besos y llantos de los amantescon su progresivo acercamientoimágenes 5 y 6-. Esta búsqueda incesantees la que convierte a la cámara, según Brecht, en un tipo de sociólogo, como se encarga de recordar Koutsourakis al recurrir a la idea brechtiana de la gestic camera en su análisis de Los idiotas (2011: 141-142). 

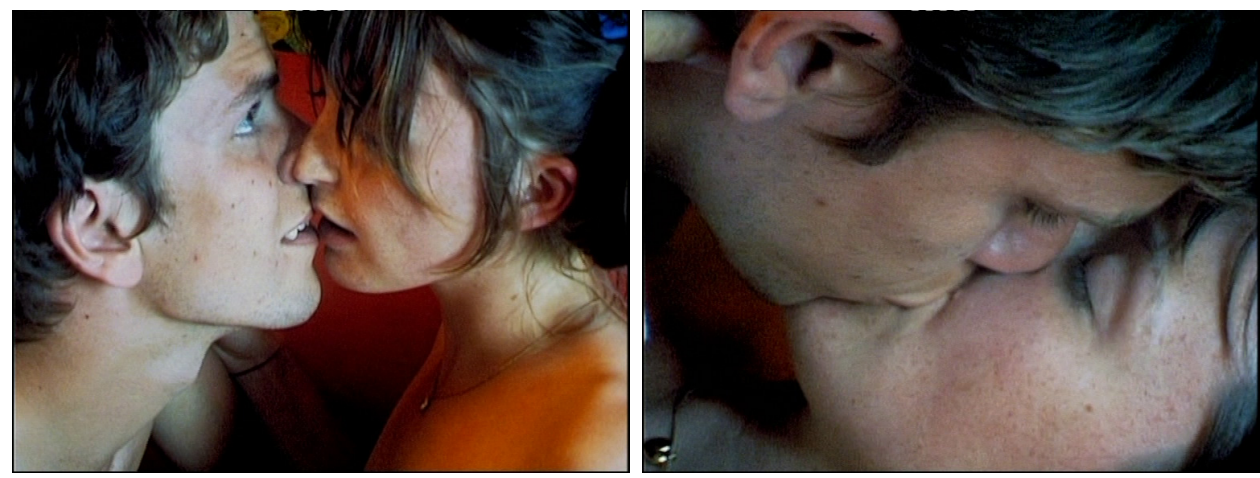

Imágenes5 y 6. [Fuente: Captura de pantalla]

En diversas ocasiones, la reducción de la distancia focal resulta un recurso fundamental para escudriñar la verdad del instante y el detalle. En la mayoría de ocasiones, el zoom in acerca en Los idiotas a la emoción más desnuda y a la intimidad más hiriente mediante la mostración de la expresión o el gesto en el que se condensa la fuerza de la acción. Quizá el momento más intenso -y más transgresor- del film en el que el zoom logra estos propósitos venga dado por el plano en el que se nos muestra la ingesta discapacitada del pastel que lleva a cabo Karen en el hogar familiar.

Independientemente del recurso o no al zoom, la minimización de la distancia entre cámara y actores logra una inusitadainmediatez en los planos destinados a hurgar en las expresiones faciales, a acercarse a la cara con la que el individuo se expone a los otros y les manifiesta su interioridad y a centrarse, sobre todo, en la mirada de unos ojos a menudo llorosos en los cuales reside gran parte del potencial expresivo humano. Es esto lo que sucedeen los momentos que hemos comentado anteriormente en que Josephine -imagen 7- y Karen -imagen 8- transitan de su estado idiota a la palabra: la corta escala insta al espectador a sentir con el personaje y, a la vez, a interrogarse por la verdad que encierran. Los idiotas se asocia de este modo con el concepto bressoniano de películas de rostros, gestos y miradas (Rubio, 2010: 18) así como con la imagen-afección de Deleuze.
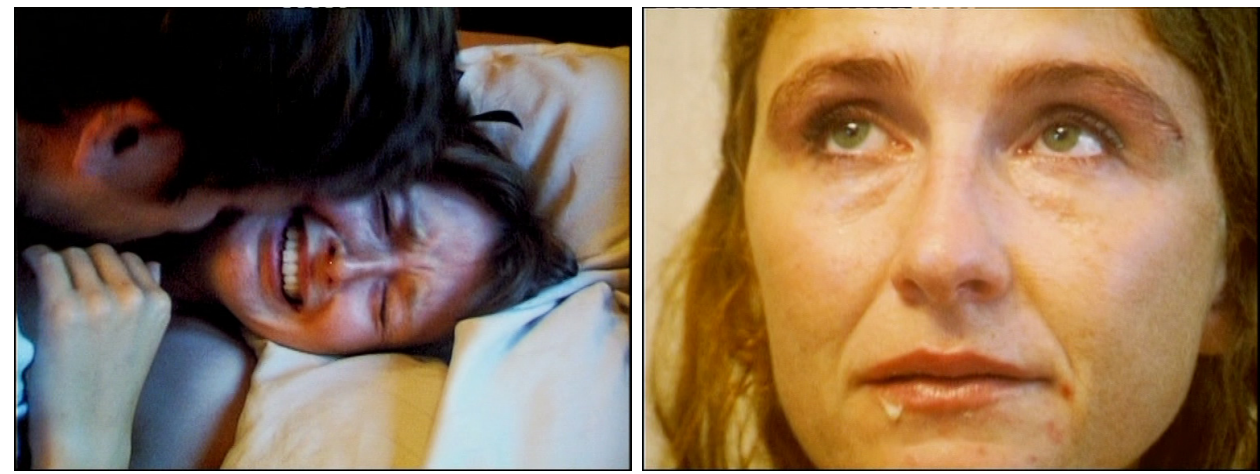

Imágenes 7 y 8 . [Fuente: Captura de pantalla] 


\subsection{La cámara-cuerpo}

Tras haber presentado un primer sentido de la reivindicación formal del cuerpo que encontramos en Los idiotas, queremos a continuación advertir un segundo sentidoen el que el discurso del film lleva a cabo tal reivindicación. Con esta finalidad continuaremos valorando el trabajo de cámara pero poniendo ahora el acento no tanto en aquello que focaliza su atención sino en la manera como realiza el reencuadre. La aludida búsqueda constante de motivos físicos, combinada con la proximidad con los personajes y el recurso de la cámara al hombro, hace que las variaciones de angulación que pretenden recoger los nuevos estímulos durante la grabación continua resulten evidentes. La cámara a menudo pivota horizontal y verticalmente en su investigación, acompañando en ocasiones estos movimientos con el propio del desplazamiento del operador.

Más allá de detenernos en dilucidar si este trabajo de cámara evidencia la presencia de un operador detrás de esta o si podríamos considerar la cámara como un personaje más, de lo que ahora queremos dejar constancia es del hecho que la cámara mira y se comporta como un cuerpo: busca, corre y escruta con sus evidentes gestos. La cámara se compromete con la realidad concreta poniéndose en la piel de la presa y no situándose en el bando del cazador (Ledo, 2004: 189) y, lejos de esconderse como invisible observadora de las acciones, nos manifiesta su condición de res extensa, se reivindica como cuerpo que ocupa un espacio y un tiempo. Su tarea no es ofrecer la "view from nowhere" encumbrada por el cine hegemónico sino la "view from now-here"

La misma escena que nos está sirviendo de base para comentar Los idiotas nos ofrece, al menos, un par de claras muestras de este tipo de reacciones corporales de la cámara. Tomemos en consideración, por ejemplo, el tipo de seguimiento y continuo reencuadre que apreciamos en los movimientos de cámara que recogen, en un solo plano, las idas y venidas de Stoffer en su intento inicial de convencer a Susanne para que participe en la orgía. Susanne aparece primeramente en plano americano, sentada en el alféizar de la ventana y hojeando una revista, sin ninguna intención de sumarse al juego sexual. Stoffer se le aproxima, y la cámara copia su acercamiento. El líder de la pandilla baja el tirante del vestido de Susanne y, ante la negativa de esta, retrocede unos cuantos pasos inmediatamente, como también lo hace la cámara. Tanto Stoffer como el operador de cámara vuelven a repetir exactamente el mismo gesto una vez más. El tercer intento de Stoffer, con el que pretende coger la mano de Susanne, es igualmente monitorizado por el operador, que continúa reencuadrando constantemente de acuerdo con la posición cambiante del joven.

Algo similar detectamos en los planos en los que la cámara oscila entre la imagen del cabecilla del grupo y la de Nana instantes antes de que comience la fiesta sexual, dirigiendo su mirada desde la perplejidad de un Stoffer que observa de pie hacia el cuerpo desnudo de Nana que yace en el suelo. La cámara apunta hacia uno y otro personaje alternativamente, como si moviera la cabeza de derecha a izquierda y de abajo arriba, sin querer perder detalle de sus reacciones y sin escondernos tampoco su interés por tales pormenores.

El juego de palabras empleado nos lo proporciona Früchtl (como se citó en Schmerheim, 2016: 115). 
Nuevamente, podemos encontrar más evidencias de esta corporificación de la cámara en otros momentos del film. La más llamativa nos remite a un pasaje clave en la relación que une a Karen y Susanne. La escena en que ambas entablan conversación junto a la ventana constituye un ejemplo muy significativo de las instintivas reacciones de una cámara humanizada en sus reencuadres, en su acercamiento -más pático que racional- a la realidad. Con imágenes que nos llevan desde el plano medio corto hasta el plano detalle, la escena se resuelve sin el tradicional juego plano-contraplano y los no menos típicos planos escorzo. La cámara encuadra una cara y después la otra, deteniéndose brevemente en las expresiones que le sirven de motivo -una palabra, una caricia, unas lágrimas-, cubriendo el ínfimo espacio que separa a las dos mujeres con un gesto que describe una minúscula panorámica horizontal. El movimiento se realiza varias veces, en un sentido y en otro, repitiendo incluso la misma dirección en dos planos contiguos yuxtapuestos con un jump cut. Con otras palabras, el ping pong propio de la convención cinematográfica es reemplazado aquí por un trabajo de cámara que más bien reproduce la mirada de quien contempla la partida de tenis de mesa desde un lateral.

La cámara muestra en esta escena, con los reencuadres que nos dirigen del rostro tremendamente expresivo de Karen a la comprensiva reacción de Susanne, su cara más humana. Podríamos decir, incluso, que el desenfoque motivado por la voluntad de acercarse a Karen hasta llegar a su alma constituye la forma más espontánea y cercana de lograr el imposible llanto de la cámara-imagen 9-.

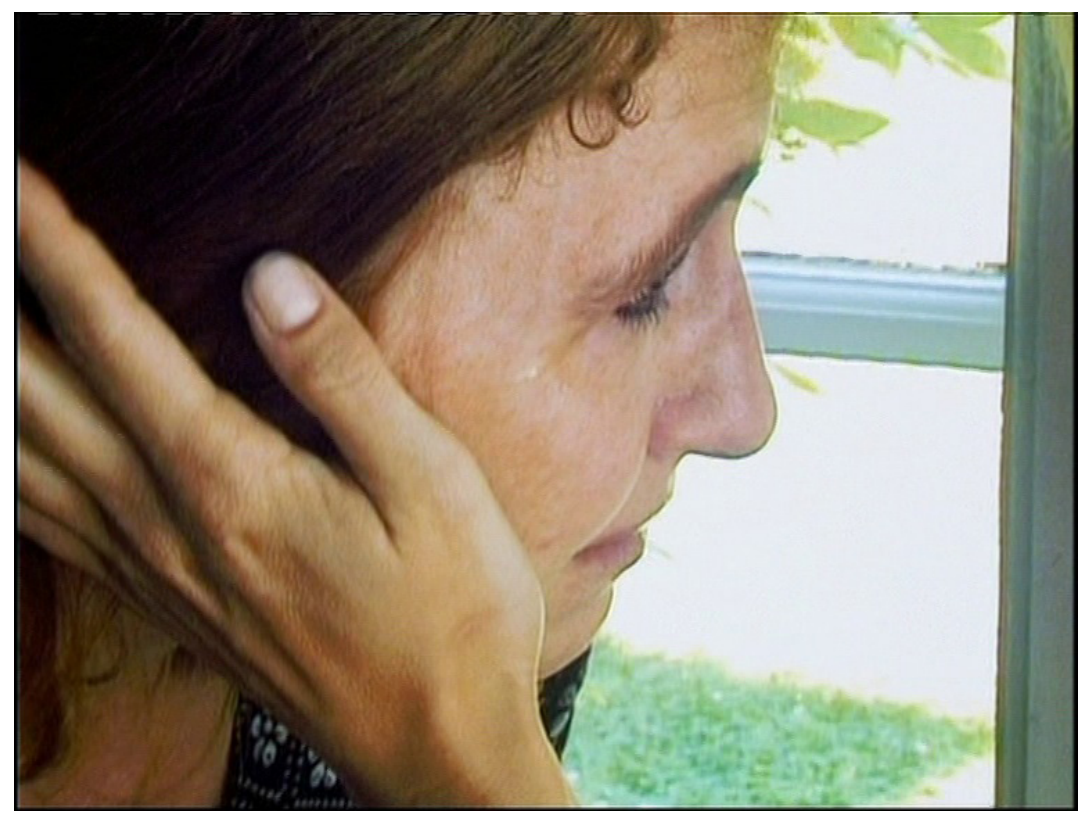

Imagen 9 [Fuente: Captura de pantalla] 


\section{Conclusiones}

Partiendo del análisis del episodio de la orgía, nuestro recorrido nos ha permitido observar las diferentes caras interconectadas de la reivindicación de la corporeidad que Los idiotas pone sobre la palestra. Atendiendo primeramente al contenido de la cinta, hemos valorado cómo la afirmación de lo físico y lo sensual que lleva a cabo el colectivo idiota se presenta como respuesta al exceso de racionalidad que imponen las normas del individualismo burgués de nuestra sociedad moderna: la transgresión de la comuna reside en lo incontrolable y volátil de su actitud, en lo dionisíaco de su incontinencia física que impide su dominio lógico. Asimismo, hemos considerado el punto de inflexión que el episodio supone en el film y hemos comprobado cómo Karen supera las limitaciones de la pandilla y apunta hacia la re-unión de cuerpo y alma mediante la comunión entre su expresión física y verbal.

A continuación, hemos centrado nuestro interés en examinar la paralela reivindicación formal del cuerpo que advertimos en el fragmento. Como hemos constatado, tal demanda no depende tanto de la desnudez de las figuras humanas que la escena nos ofrece sino del resultado que von Trier obtiene de la aplicación de su técnica idiota consistente en "apuntar y disparar". El análisis de estatécnica nos ha permitido reparar en una monitorización exhaustiva de los cuerpos que se postula como camino hacia esa verdad que el Manifiesto Dogma propone extraer de los personajes y del cuadro de la acción y que en el film de von Trier nos remite en última instancia a los cuerpos de los actores. Tal y como hemos visto, son las trayectorias de estos cuerpos las que nos facilitan el acceso al conjunto del espació profílmico y, sobre todo, es la indagación de las minúsculas reacciones del rostro con los planos cortos y el zoom in la que revela la verdad que guardan los personajes, como detectábamos al atender a los momentos de transformación de Josephine y, especialmente, Karen. Podemos concluir ahora, pues, que no parece haber para la cámara de von Trier separación sino unidad entre el alma y el cuerpo del personaje: para la técnica consistente en "apuntar y disparar" - como para Cavell o para la Karen que trasciende las dicotomías que asume el grupo-, lo físico no es una barrera para llegar al alma sino la mejor manera de acceder a ella.

Por último, la indagación del point and shoot style nos ha llevado a reflexionar en torno a la somatización de la cámara que detectamos en gran parte del film y que marca notablemente su estilo. Si bien comentábamos que la fijación por los cuerpos entronca con la voluntad de escapar del dominio cinematográfico de la realidad -y cumplir así con la abstención estética que promulga Dogma 95-, podemos mantener ahora que la corporificación de la cámara evidencia la mano -el cuerpo- que la dirige y desoculta el hecho fílmico que posibilita la revelación de mundo. La intención mostrativa de Los idiotas acaba, de este modo, haciéndonos visibles-incluso de manera estrictamente literal- los instrumentos del medio que permiten tal mostración, revelándonos - de una manera más explícita que aquella a la que estamos acostumbrados- el proceso cinematográfico y la instancia enunciadora que hay detrás.

Aunque por motivos analíticos y expositivos hayamos disociado entre contenido y forma de Los idiotas, no podemos obviar que la experiencia del film remite a los efectos que genera la película entendida como un todo que es más que la mera suma de sus partes. Y en nuestro caso, ese todo supone un alud de pathos que la cinta de von Trier descarga por vías distintas sobre el espectador, instándolo a abandonar su habitual estatus de consumidor pasivo, a aceptar su papel de otorgador de sentido 
y a lanzarse a la aproximación existencial a la película. Porque el espectador que pretende Los idiotas es mucho más que la mente que tiene que entender el happy end de los productos de la industria como conclusión necesaria que se deriva de unas premisas fijadas sólidamente al inicio del metraje: su espectador no es el ojo desencarnado que el cine hegemónico pretende, sino que se encuentra más próximo al individuo de carne y hueso inscrito en la película que perseguíaVertov. Si bien toda película, obviamente, cuenta con espectadores que -también- son cuerpo, la poliédrica experiencia corpórea que Los idiotas ofrece enfatiza la necesidad de una respuesta igualmente somática -que no puede reducirse a la distancia reflexiva y a lo meramente epistemológico- por parte de su audiencia.

Por mucho que al inicio de nuestro escrito apuntáramos al cuestionamiento de los límites de la pornografía que Los idiotas comportaba con su inclusión de escenas como la de la orgía, podemos afirmar ahora que el auténtico potencial transgresor del film reside en la imbricación de las diversas caras de su reivindicación de la corporeidad y en sus implicaciones políticas. En términos políticos entendíamos antes la marcha de Karen del hogar familiar y también en clave política podemos valorar la propuesta formal de una práctica filmica que hace frente a las rutinas del modelo cinematográfico dominante y que, partiendo del cuerpo, nos aleja de una concepción unívoca de la realidad y nos abre a la contingencia y la indeterminación. Tanto temática como formalmente, en última instancia, Los idiotas presenta el cuerpo como base desde la cual articular la respuesta al logocentrismo de nuestra cultura moderna.

Por tanto, si antes remarcábamos cómo la película encabezaba una serie de títulos que destacaban por su recurso al sexo explícito, cabe ahora situar Los idiotas dentro de ese grupo de cintas contemporáneas que se esfuerzan por dejar patente que su afirmación del cuerpo no es solo un gesto estético, sino también político. Cabría preguntarse en futuras investigaciones hasta qué punto ambos listados de films podrían o no solaparse, hasta qué extremo ambas tendencias han seguido una evolución paralela o, quizá lo más importante, en qué medida la crisis -económica, social, política, ¿sistémica? -que venimos sufriendo ha reavivado el cine del cuerpo y la alternativa vital que suele proponer. De lo que no cabe tanta duda es que aquellas películas que, de una u otra manera, exploran el tabú de la sexualidad ofrecen un fecundo terreno de análisis para la reflexión en torno al cuerpo'.

\section{Bibliografía}

Cavell, S. (2003). Reivindicaciones de la razón. Madrid: Síntesis.

Cavell, S. (2009). Más allá de las lágrimas. Madrid: Antonio Machado Libros.

Deleuze, G. (1984). La imagen-movimiento. Estudios sobre cine 1. Barcelona: Paidós.

Deleuze, G. (1987). La imagen-tiempo. Estudios sobre cine 2. Barcelona: Paidós.

Guillamón, S. y Belmonte, J. (2020). "Sexualidad, política del cuerpo y función socioeducativa del cine en Touch Me Not (Adina Pintilie, 2018)". Fotocinema. Revista cientifica de cine y fotografia, $\mathrm{n}^{\mathrm{o}} 21$, pp. 373-401. https://doi.org/10.24310/Fotocinema.2020. vi21.10017

Sirvan como ejemplo el análisis que realiza Koutsourakis (2012: 96-103) de la antes mencionada Canino y el artículo de Guillamón y Belmonte (2020) sobre Touch Me Not (Numă atinge-mă, Adina Pintilie, 2018). 
Jerslev, A. (2002). "Dogma 95, Lars von Trier's The Idiots and the 'Idiot Project'”. En Anne Jerslev (ed.), Realism and "Reality" in Film and Media. Copenhague: Museum Tusculanum Press, pp. 41-65.

Koutsourakis, A. (2011). “A Film Should Be Like a Stone in Your Shoe”: A Brechtian Reading of Lars von Trier. Tesis doctoral. Brighton: University of Sussex. Recuperado de http://sro.sussex.ac.uk/7458/ (Fecha de acceso: 21/11/2020).

Koutsourakis, A. (2012). "Cinema of the Body: The Politics of Performativity in Lars von Trier's Dogville and Yorgos Lanthimos' Dogtooth". Cinema: Journal of Philosophy and the Moving Image, 3. pp, 84-108. Recuperado de: http://static1.1.sqspcdn.com/static/f/906805/21523943/1357327968610/3_Koutsourakis.pdf?token=odUf1FEvaf\%2FrZaPJ\%2F0dd3iAmn2k\%3D (Fecha de acceso: 21/11/2020).

Ledo, M. (2004). Del Cine-ojo a Dogma 95. Paseo por el amor y la muerte del cinematógrafo documental. Barcelona: Paidós.

Mendíbil, Á., García García, F. y García Guardia, M. L. (2017). "Narratología porno. Una lectura semiótica de Tras la puerta verde". Fotocinema. Revista cientifica de cine y fotografia, $\mathrm{n}^{\mathrm{o}}$ 15, pp. 155-177. https://doi.org/10.24310/Fotocinema.2017.v0i15.3504

Ribes, D. (2009). "La filosofía y lo ordinario". En David Pérez Chico y Moisés Barroso (eds.), Encuentros con Stanley Cavell. Madrid: Plaza y Valdés, pp. 213-242.

Rockwell, J. (2003). The Idiots. Londres: British Film Institute. https:/doi. org/10.5040/9781838712938

Rubio, A. (2010). “El Dogma danés”. Biblioteca On-line de Ciências da Comunicação, pp. 1-23. Recuperado de http://bocc.ufp.pt/pag/alcover-rubio-el-dogma-danes.pdf (Fecha de acceso: $21 / 11 / 2020)$.

Schmerheim, P. (2016). Skepticism Films: KnowingandDoubtingtheWorld in Contemporary Cinema. New York: Bloomsbury.http://dx.doi.org/10.5040/9781501311000

Simons, J. (2007). Playing the Waves: Lars von Trier's Game Cinema. Amsterdam University Press: Amsterdam. https://doi.org/10.5117/9789053569795

Sjöholm, C. (2003). "Kristeva and The Idiots". Radical Philosophy, 122, pp. 35-39. Recuperado de://www.radicalphilosophyarchive.com

Stevenson, J. (2005). Lars von Trier. Barcelona: Paidós.

Vinterberg, T. y von Trier, L. (1995). "The Dogme 95 Manifesto \& TheVow of Chastity". Recuperado de https://www.dogme95.dk (Fecha de acceso: 21/11/2020). 